\title{
Association Between Patient- and Physician-Reported Outcomes in Patients with Moderate-To-Severe Plaque Psoriasis Treated with Biologics in Real Life (PSO-BIO- REAL)
}

Jean-Philippe Lacour • Anthony Bewley · Edward Hammond •

Jes B. Hansen · Laura Horne · Carle Paul - Kristian Reich •

Julien Seneschal • Clara De Simone · Anne Sohrt · Matthias Augustin •

Giovanni Pellacani

Received: June 16, 2020 / Published online: August 6, 2020

(C) The Author(s) 2020

\section{ABSTRACT}

Introduction: Clinical trials have shown that psoriasis patients who achieve complete skin clearance are more likely to report no

Digital Features To view digital features for this article go to https://doi.org/10.6084/m9.figshare.12639260.

J.-P. Lacour $(\bowtie)$

Department of Dermatology, Archet 2 Hospital, University Hospital of Nice, Nice, France

e-mail: lacour@unice.fr

\section{A. Bewley}

Department of Dermatology, Barts Health NHS

Trust, London, UK

A. Bewley

Queen Mary School of Medicine, University of London, London, UK

E. Hammond · L. Horne

AstraZeneca, Gaithersburg, MD, USA

J. B. Hansen · A. Sohrt

LEO Pharma A/S, Ballerup, Denmark

C. Paul

Toulouse University and Larrey Hospital, Toulouse,

France

K. Reich

Translational Research in Inflammatory Skin

Diseases, Institute for Health Services Research in

Dermatology and Nursing, University Medical

Center Hamburg-Eppendorf, Hamburg, Germany impairment in health-related quality of life (HRQoL) and no psoriasis symptoms versus patients who achieve almost complete skin clearance. However, real-world data are lacking. The objective of this study was to estimate the real-world proportion of moderate-to-severe psoriasis patients on biologic treatment who

K. Reich

Skinflammation ${ }^{\circledR}$ Center, Hamburg, Germany

J. Seneschal

Department of Dermatology and Paediatric

Dermatology, National Reference Centre for Rare

Skin Diseases, Saint-André Hospital, University of Bordeaux, Bordeaux, France

C. De Simone

Department of Dermatology, Catholic University of the Sacred Heart, Fondazione Policlinico

Universitario “A. Gemelli" IRCCS, Rome, Italy

M. Augustin

Institute for Health Services Research in

Dermatology and Nursing (IVDP), University

Medical Centre Hamburg-Eppendorf (UKE),

Hamburg, Germany

G. Pellacani

Department of Dermatology, University of Modena and Reggio Emilia, Modena, Italy 
achieved a Psoriasis Symptom Inventory (PSI) total score of 0 (PSI 0; no symptoms) and a Dermatology Life Quality Index (DLQI) score of 0/1 (DLQI 0/1; no impact on HRQoL), and to study the relationship between patient-reported symptoms and HRQoL versus physician-reported psoriasis severity (Psoriasis Area and Severity Index [PASI]).

Methods: The PSO-BIO-REAL study was a multinational, prospective, real-world, non-interventional study that included patients aged $\geq 18$ years with moderate-to-severe plaque psoriasis who had initiated biologic therapy (either biologic-naïve or had switched biologics [biologic-experienced]). Psoriasis symptoms were evaluated using the PSI, and HRQoL was assessed using the DLQI. Assessments were conducted at baseline and at 6 and 12 months after initiating biologic treatment. Associations between PSI and DLQI with PASI were evaluated using Spearman correlation coefficients. Posthoc analyses evaluated individual PSI items and the association to PASI response, DLQI and PSI by index biologic.

Results: At 12 months, $25.5 \%$ of patients achieved PSI 0, and 51.2\% achieved DLQI 0/1, with greater proportions achieving these scores among biologic-naïve than among biologic-experienced patients. There was a moderate-tostrong correlation between PSI and DLQI scores and PASI scores, with $64.8 \%$ of patients with absolute PASI 0 and $19.4 \%$ with absolute PASI $>0 \leq 2$ achieving PSI 0 (6 and 12 months pooled). Achievement of response varied by index biologic.

Conclusion: This study demonstrates that in a real-world setting patients' QoL improves with skin clearance. The results also demonstrate that the correlation between skin clearance and improvements in HRQoL (DLQI) and psoriasis symptoms (PSI) is not complete, which highlights the importance of considering both patient- and physician-reported outcomes in the assessment of psoriasis treatment outcomes.

Keywords: Biologic therapy; Complete skin clearance; DLQI; Health-related quality of life; Patient-reported outcomes; Plaque psoriasis; Psoriasis symptom inventory; Real-world evidence

\section{Key Summary Points}

\section{Why carry out this study?}

Plaque psoriasis has a substantial negative impact on patients' quality of life.

Clinical trials have demonstrated that the achievement of complete skin clearance versus almost complete skin clearance is associated with clinically meaningful differences in health-related quality of life (HRQoL). However, real-world data are lacking.

The primary objective of this study was to evaluate complete skin clearance, and to assess the impact of biologic treatment on HRQoL and symptoms of psoriasis in realworld settings

\section{What was learned from the study?}

Greater degrees of skin clearance were associated with more substantial improvements in HRQoL and with fewer psoriasis symptoms.

The correlation between patient- and physician-reported outcome measures was not complete, emphasizing the importance of considering both patientand physician-reported outcomes when assessing treatment outcomes.

\section{INTRODUCTION}

Psoriasis is characterized by red scaling skin plaques that, together with comorbidities, can have a substantial negative impact on patients' quality of life (QoL) due to physical dysfunction, psychological issues and social ramifications of the disease [1-3]. The negative impact of moderate-to-severe psoriasis on QoL is often similar to or greater than that of other major medical conditions, including arthritis, diabetes, hypertension, heart disease and cancer [4]. 
A meaningful outcome of treatment for patients with psoriasis is an avoidance of impairment in their daily lives [5]. Modern biologic therapies, such as interleukin-17 and IL-23 inhibitors, make complete skin clearance, as measured by the Psoriasis Area and Severity Index (PASI), a desirable and achievable outcome for patients with moderate-to-severe psoriasis [6]. Clinical trials have demonstrated that the achievement of complete skin clearance (PASI 100) versus almost complete skin clearance (PASI 90 to $<100$, indicating 90 to $<100 \%$ improvement) is associated with clinically meaningful differences in health-related QoL (HRQoL) and burden of skin symptoms $[5,7,8]$. Patients with PASI 100 were more likely to report that their overall psoriasis signs and symptoms were not at all severe and that their disease had no effect on their symptoms and feelings, and they were also less likely to report pain $[5,7,8]$. It therefore appears that patients who achieve complete skin clearance and those who achieve almost complete skin clearance may represent distinct disease states, and their psoriasis experiences and perceptions may differ in meaningful ways [9].

However, data from controlled clinical trials may not be generalizable to broader populations or real-world practice due to, for example, strict inclusion and exclusion criteria being unrepresentative of the patient populations encountered in clinical practice [10]. The relationships between rates of complete skin clearance, symptom improvement and HRQoL have not been fully characterized in clinical practice [7].

The Dermatology Life Quality Index (DLQI) is a dermatology-specific HRQoL assessment tool consisting of ten questions covering six domains: symptoms and feelings, daily activities, leisure, work and school, personal relationships and bother with treatment, with an overall potential score ranging from 0 (not affected at all) to 30 (very much affected). A DLQI score of $0 / 1$ indicates no impact of condition on HRQoL [11, 12]. The Psoriasis Symptom Inventory (PSI) is a psoriasis-specific, patient-reported measure of psoriasis symptom severity developed by Amgen [13]. The PSI quantifies patients' perception of eight specific psoriasis symptoms: itch, redness, scaling, burning, stinging, cracking, flaking and pain $[13,14]$. Each symptom (or item) is scored from 0 (not at all) to 4 (very severe). The PSI total score is the sum of the eight items and can range from 0 to 32 . Assessment and validation of the PSI have shown strong internal consistency, test-retest reliability and responsiveness to changes in clinical studies $[13,15]$.

We report here the results from the large, multinational, observational, PSOriasis Treated with BIOlogics in REAL Life (PSO-BIO-REAL) study, the primary objective of which was to evaluate complete skin clearance and to assess the impact of biologic treatment on HRQoL and symptoms of psoriasis in real-world settings (previously reported) [16]. The aim of the current analysis was to assess the proportion of patients with limited symptoms and experiencing no impact on their HRQoL according to the PSI and DLQI, and to evaluate any association between PASI and these patient-reported outcomes (PROs).

All subjects provided informed consent to participate in the study. The study received approval from the relevant Institutional Review Boards and was performed in accordance with the Helsinki Declaration of 1964 and its later amendments.

\section{METHODS}

The PSO-BIO-REAL study was a 12-month, multinational, prospective, observational study that included adult patients from five countries (USA, France, Italy, Germany, UK), and its methodology has been described previously [16]. In brief, eligible patients were aged $\geq 18$ years, diagnosed with moderate-tosevere plaque psoriasis and either initiating therapy with an approved biologic for the first time (biologic-naïve) or switching to a different approved biologic (biologic-experienced). Study assessments (PASI, static Physician's Global Assessment [sPGA), static Patient's Global Assessment [sPtGA], PSI, DLQI, treatment satisfaction and global health status) were collected at baseline and at follow-up visits at 6 and 
Table 1 Baseline characteristics of patients enrolled in the PSO-BIO-REAL study

\begin{tabular}{|c|c|c|c|c|c|c|c|}
\hline \multirow[t]{2}{*}{ Characteristic } & \multirow{2}{*}{$\begin{array}{l}\text { Biologic- } \\
\text { näve }^{\mathrm{a}}(N=509)\end{array}$} & \multirow{2}{*}{$\begin{array}{l}\text { Biologic- } \\
\text { experienced } \\
(N=337)\end{array}$} & \multicolumn{4}{|c|}{ Index biologic ${ }^{c}$} & \multirow[t]{2}{*}{ Overall $(N=846)$} \\
\hline & & & $\begin{array}{l}\text { Adalimumab } \\
(n=343)\end{array}$ & $\begin{array}{l}\text { Etanercept } \\
(n=143)\end{array}$ & $\begin{array}{l}\text { Ustekinumab } \\
(n=256)\end{array}$ & $\begin{array}{l}\text { Secukinumab } \\
(n=76)\end{array}$ & \\
\hline Age, years, mean (SD) & $45.7(14.0)$ & $50.0(12.9)$ & $46.4(14.0)$ & $49.4(14.6)$ & $46.0(13.3)$ & $50.8(11.5)$ & $47.4(13.8)$ \\
\hline Male, $n(\%)$ & $321(63.1)$ & $214(63.5)$ & $207(60.3)$ & $98(68.5)$ & $158(61.7)$ & $52(68.4)$ & $535(63.2)$ \\
\hline White, $n(\%)$ & $473(92.9)$ & $308(91.4)$ & $312(91.0)$ & $139(97.2)$ & $232(90.6)$ & $70(92.1)$ & $781(92.3)$ \\
\hline $\begin{array}{l}\text { BMI, } \mathrm{kg} / \mathrm{m}^{2} \text {, mean } \\
\quad(\mathrm{SD})(n=830)\end{array}$ & $28.8(6.8)$ & $30.3(6.7)$ & $29.0(6.7)$ & $29.0(6.7)$ & $29.2(6.8)$ & $31.0(5.7)$ & $29.4(6.8)$ \\
\hline $\begin{array}{l}\text { Duration of psoriasis, } \\
\text { years, mean }(\mathrm{SD})\end{array}$ & $17.1(13.3)$ & $20.4(12.8)$ & $17.8(12.9)$ & $19.7(14.7)$ & $18.2(13.1)$ & $20.3(12.7)$ & $18.4(13.2)$ \\
\hline $\begin{array}{l}\text { Psoriatic arthritis, yes, } \\
n(\%)\end{array}$ & $119(23.4)$ & $119(35.3)$ & $96(28.0)$ & $46(32.2)$ & $67(26.2)$ & $22(28.9)$ & $238(28.1)$ \\
\hline $\begin{array}{l}\text { Prior biologic use, } \\
n(\%)\end{array}$ & $2(0.4)$ & $337(100.0)$ & $88(25.7)$ & $32(22.4)$ & $154(60.2)$ & $49(64.5)$ & $339(40.1)$ \\
\hline PASI, mean (SD) & $14.38(8.5)$ & $14.18(10.5)$ & $13.9(8.5)$ & $14.0(8.4)$ & $13.8(9.4)$ & $16.6(12.1)$ & $14.3(9.3)$ \\
\hline PSI, mean (SD) & $17.4(7.7)$ & $17.1(7.8)$ & $17.0(7.6)$ & $16.5(7.6)$ & $17.5(7.6)$ & $18.4(7.99)$ & $17.3(7.8)$ \\
\hline DLQI, mean (SD) & $12.9(7.6)$ & $11.6(7.7)$ & $12.1(7.3)$ & $11.9(7.4)$ & $12.6(7.8)$ & $13.8(8.4)$ & $12.4(7.6)$ \\
\hline
\end{tabular}

BMI Body mass index, DLQI Dermatology Life Quality Index, PASI Psoriasis Area and Severity Index, PSI Psoriasis Symptom Inventory, SD standard deviation

a Subjects who were not exposed to biologic treatment prior to study enrolment

b Subjects who received biologic treatment prior to study enrolment but switched to a different biologic at study entry

c Two patients received certolizumab pegol and 26 patients received infliximab. Aggregated baseline characteristics for these patients have not been reported separately by index biologic because of low numbers

12 months following initiation of therapy with the index biologic.

The primary outcome variable of this study was the effectiveness of biologics, based on PASI 100 after 6 months following the initiation of a biologic. Secondary outcome variables included the PSI and DLQI outcomes.

This analysis descriptively quantified the proportion of patients with PSI response (defined as score $\leq 8$ on the total PSI scale, with a score for no single item $>1$ ), PSI 0 (no disease activity) and DLQI 0 or $0 / 1$ (no effect on patient's life) at 6 and 12 months after treatment initiation among all patients. Other objectives were to describe the distribution of treatment response according to PSI and DLQI scores across the study population (biologic naïve or biologic experienced and according to both absolute PASI response and relative PASI improvement) and to evaluate any association between clinical measures (PASI) and PROs (PSI and DLQI) using Spearman's correlation coefficient at 6 and 12 months. Post hoc analyses evaluated individual PSI items according to
PASI response (pooled 6 and 12 months), and DLQI and PSI per index biologic (at 6 and 12 months). In this analysis, the effectiveness in treatment groups with $\geq 30$ patients was reported at baseline and assessed until the end of study or switch in biologic treatment. All data were analyzed descriptively as observed; no imputation method was used for missing values. For continuous measures, mean, standard deviation (SD), minimum, median and maximum were used, and for ordinally data, number and proportion were tabulated. In analyses by the treatment that patients were either initiated on or switched to at study initiation (index biologic), we report number and proportion switched at months 6 and 12, and have disregarded data after the switch to new treatment. All quantitative analyses were conducted using SAS version 9.4 (SAS Institute, Cary, NC, USA).

To investigate the association between skin clearance and PROs, we analyzed the proportion of patients achieving PSI 0 and DLQI scores of $0 / 1$ according to PASI response categories. The linear trend between PRO responses and PASI 

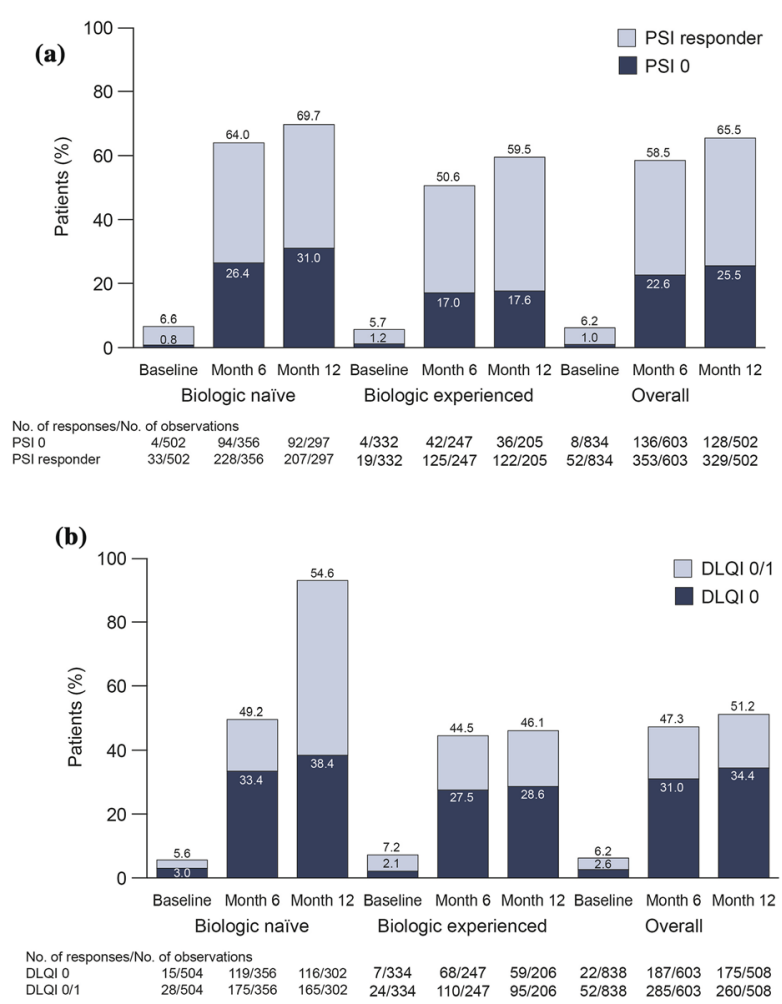

Fig. 1 Achievement of PSI 0 (no disease activity) or PSI response (a) and DLQI 0/DLQI 0/1 (no effect on patient's life) (b) at baseline and at 6 and 12 months following treatment initiation, overall and by prior biologic use (biologic naïve and biologic experienced). Percentages are based on the number of observed (not including missing) patients. DLQI Dermatology Life Quality Index, PSI Psoriasis Symptom Inventory

response categories was evaluated by applying an adjusted logistic regression. The correlations between PASI scores and PSI/DLQI scores were evaluated with Spearman's correlation coefficient $[17,18]$.

\section{RESULTS}

Baseline characteristics for all patients are summarized in Table 1 . In total, 846 patients were enrolled in the study, of whom $60.2 \%$ were biologic naïve. Most patients were male (63.2\%), and the mean age was 47.4 (SD 13.8) years. At baseline, the mean PASI score was 14.3 (SD 9.3). Both patient- and physician-measured global assessments (sPtGA and sPGA],
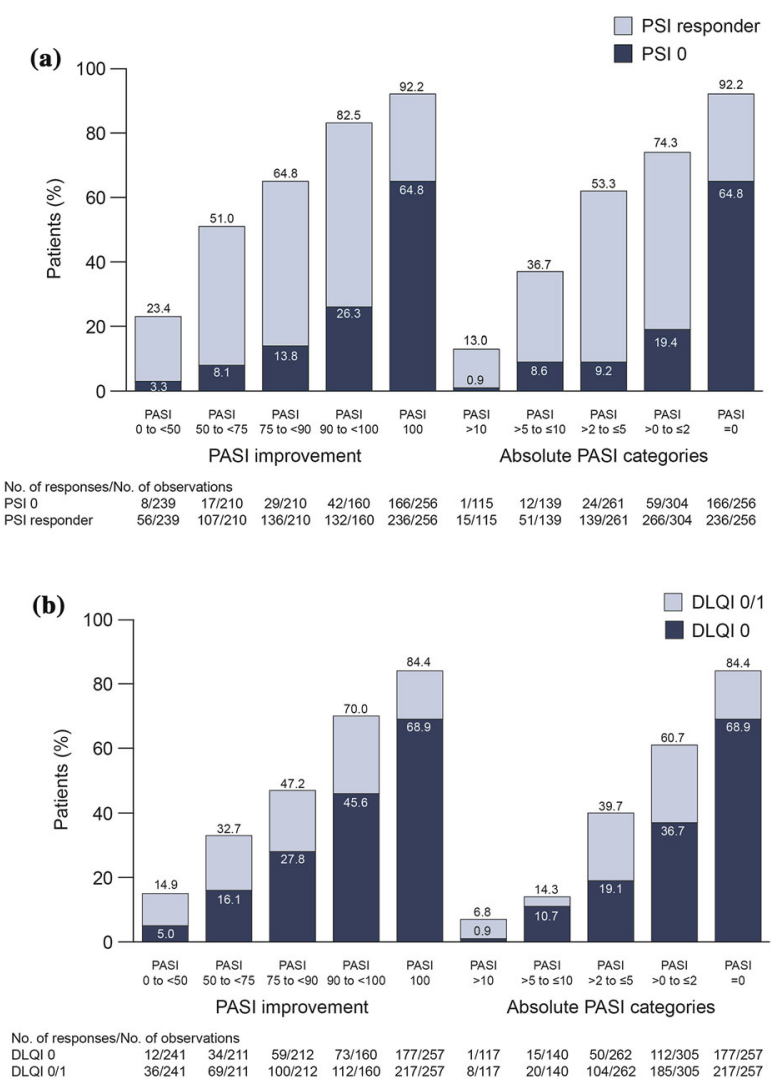

Fig. 2 Distribution of PASI categories and absolute PASI scores in patients who achieved PSI 0/PSI response (a) and DLQI 0/DLQI 0/1 (b) (pooled 6 and 12 months). PASI Psoriasis Area and Severity Index

respectively) suggested moderate-to-severe symptoms, although patients reported greater symptom severity than physicians. The mean baseline PSI and DLQI scores were 17.3 (SD 7.8) and 12.4 (SD 7.6), respectively.

PSI assessments were available for 603 patients at month 6 and 502 patients at month 12. At months 6 and 12, 22.6 and $25.5 \%$ of patients, respectively, achieved PSI 0 , and 58.5 and $65.5 \%$ of patients, respectively, were PSI responders (Fig. 1a). A greater proportion of biologic-naïve patients achieved PSI 0 compared with biologic-experienced patients (31.0 vs. $17.6 \%$ at month 12). At months 6 and 12, 603 and 508 patients, respectively, were available for assessment of DLQI. Analysis of DLQI results showed that 47.3 and $51.2 \%$ of patients achieved DLQI $0 / 1$ and that 31.0 and $34.4 \%$ of patients achieved DLQI 0 at months 6 and 12, 

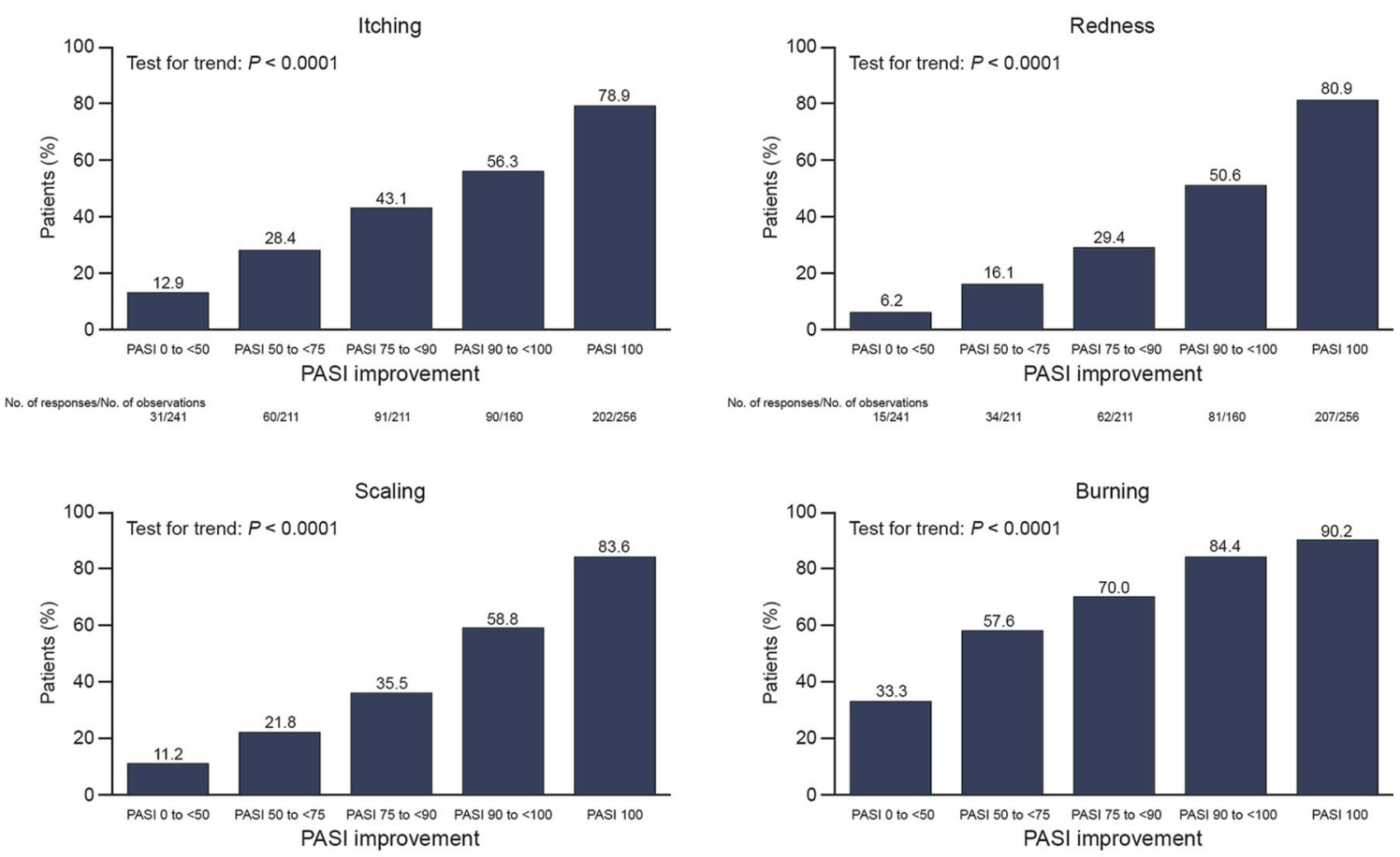

$\begin{array}{lllll}\text { No. of responses/No. of observations } & \\ 27 / 241 & 46 / 211 & 75 / 211 & 94 / 160 & 214 / 256\end{array}$

\section{PASI improvement}
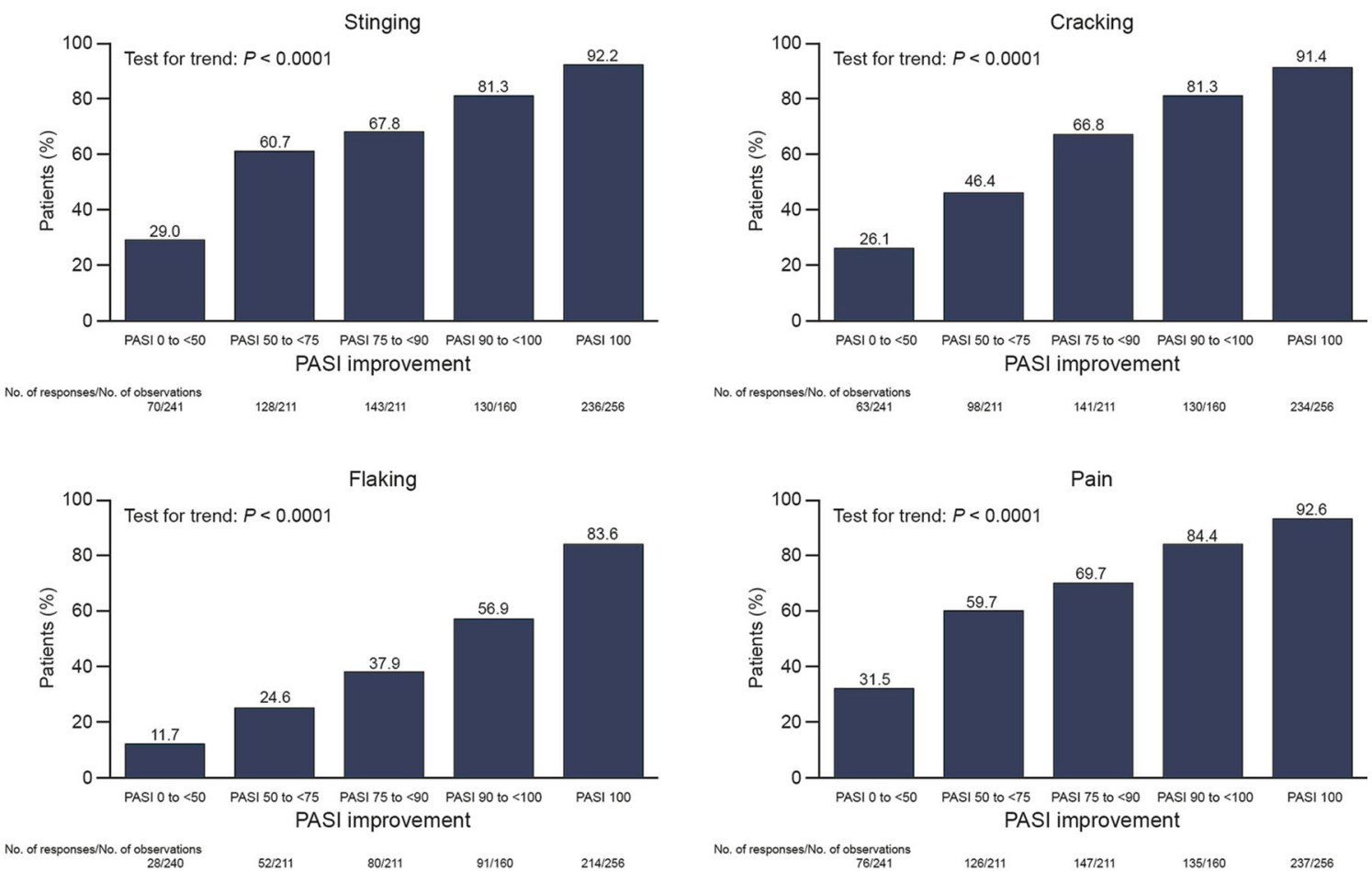

Fig. 3 Proportions of patients achieving PSI 0 for each PSI item according to PASI response (pooled 6 and 12 months). PASI Psoriasis Area and Severity Index, PSI Psoriasis Symptom Inventory 
Table 2 Spearman correlation between Psoriasis Area and Severity Index and Dermatology Life Quality Index and Psoriasis Symptom Inventory, respectively

\begin{tabular}{lll}
\hline Assessment time & DLQI $(\boldsymbol{n}=\mathbf{6 7 2})$ & PSI $(\boldsymbol{n}=\mathbf{6 7 2})$ \\
\hline Month 6 & 0.58 & 0.64 \\
Month 12 & 0.63 & 0.68 \\
\hline
\end{tabular}

All correlations were statistically significant $(P<0.0001)$ $\rho=0.00-0.19$ is a very weak association; $\rho=0.20-0.39$ is a weak association; $\rho=0.40-0.59$ is a moderate association; $\rho=0.60-0.79$ is a strong association; $\rho=0.80-1.0$ is a very strong association $[16,17]$

respectively (Fig. 1b). A higher proportion of biologic-naïve patients achieved DLQI $0 / 1$ versus biologic-experienced patients (54.6 vs. $46.1 \%$, respectively, at month 12 ).

Patients were more likely to achieve PSI 0 if they also achieved greater degrees of skin clearance. This trend was seen for both absolute PASI response and relative PASI improvement (Fig. 2a). There was an increase in the proportion of patients who achieved PSI 0 among those with complete skin clearance (PASI 100, $64.8 \%$ ) versus those with almost complete skin clearance (PASI 90 to $<100,26.3 \%$ ) at month 6. For all items of the PSI score, a significant trend in the correlations between the proportion of patients with no symptoms and PASI response was observed (Fig. 3). Patients were also more likely to achieve DLQI $0 / 1$ if they achieved greater degrees of skin clearance (Fig. 2b), with a similar increase observed between PASI 90 to $<100$ and PASI $100 \quad(70.0$ vs. $84.4 \%$, respectively).

Spearman's rank correlation analysis was performed to determine the relationship between PASI scores and PSI and DLQI, at months 6 and 12. All correlations were statistically significant and ranged between 0.58 and $0.68(P<0.0001)$ (Table 2$)$.

Achievement of PSI 0 in patients who continued their index biologic treatment to months 6 and 12 ranged from $14.6 \%$ of those on etanercept to $25.8 \%$ of those taking adalimumab at month 6, and from 22.9\% (ustekinumab) to $29.9 \%$ (etanercept) at month 12 . The attainment of PSI response ranged from
$45.5 \%$ of those on secukinumab to $68.0 \%$ of those taking adalimumab at month 6 (Fig. 4a); similar results were observed at 12 months, with slightly higher proportions of patients achieving PSI response than at month 6 . Achievement of DLQI 0 and DLQI 0/1 ranged from $20.2 \%$ of patients on etanercept to $36.9 \%$ of those taking adalimumab for DLQI 0 , and from $39.3 \%$ (etanercept) to $53.0 \%$ (ustekinumab) for DLQI $0 / 1$ at 6 months, again with slightly higher proportions of responders at month 12 (Fig. 4b). Data for patients who switched to another biologic were excluded from this analysis after the switch. The proportions of patients who switched to another treatment during the study were $18.9 \%$ of those on etanercept, $15.2 \%$ of those on adalimumab and $6.6 \%$ of those on ustekinumab and secukinumab. Two biologics were not evaluated due to low patient numbers in both groups: infliximab $(n=26)$ and certolizumab pegol $(n=2)$.

\section{DISCUSSION}

The PSO-BIO-REAL study was an observational study reporting on complete skin clearance and PROs in psoriasis, which enrolled patients from five countries who were initiating treatment with a biologic, either for the first time or switching from another biologic. This analysis shows that patient QoL improved with skin clearance, but that the correlation between PASI response and PROs was not complete.

As expected, greater degrees of skin clearance were associated with more substantial improvements in HRQoL and burden of skin symptoms, as measured by DLQI and PSI. Importantly, the analysis showed that attainment of complete skin clearance is associated with a considerably larger proportion of patients achieving symptom resolution than almost complete skin clearance. From patients' perspectives, this may indicate that the symptom burden is greater for patients who have only partially cleared skin, even for PASI 90 and above, compared with complete clearance, and therefore highlights the importance of achieving complete skin clearance. These observations are consistent with the findings of previous 


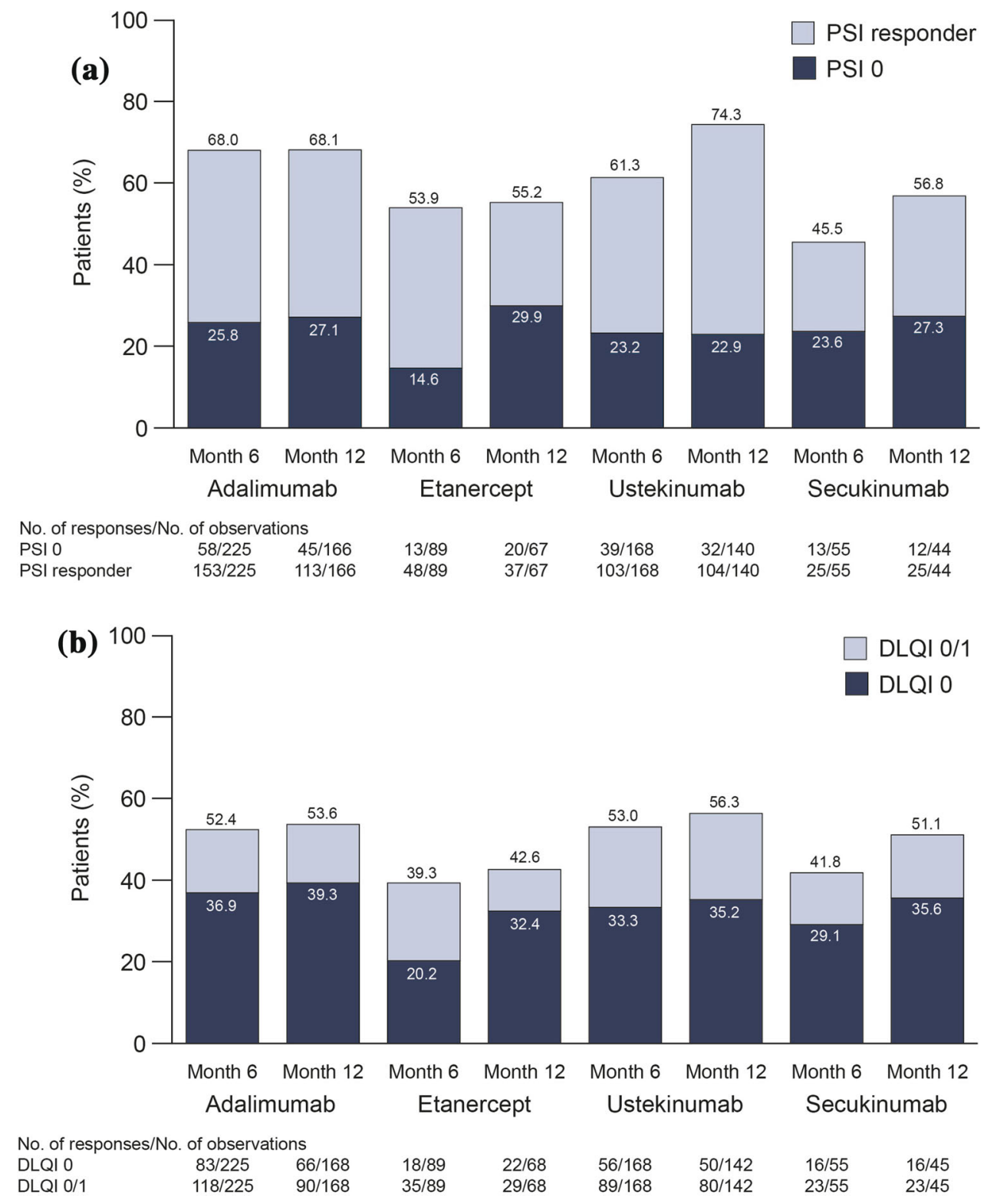

Fig. 4 Achievement of PSI 0/PSI response (a) and DLQI $0 /$ DLQI $0 / 1$ (b) at 6 and 12 months by index biologic. Note: Two biologics are not illustrated due to low patient

clinical and observational studies, which demonstrated that attainment of PSI 0 or DLQI $0 / 1$ was significantly higher among patients who achieved complete skin clearance (defined as PASI 100 or sPGA 0) compared with those who achieved almost complete skin clearance (PASI 75 to $<100$ or sPGA 1) $[5,7-9,19]$. In addition, patients with complete skin clearance numbers in both groups: infliximab $(n=26)$ and certolizumab pegol $(n=2)$. DLQI Dermatology Life Quality Index, PSI Psoriasis Symptom Inventory

had fewer signs and symptoms of psoriasis and were more likely to report no impact of psoriasis on HRQoL compared with patients who had almost complete skin clearance [5, 7-9, 19].

A significant proportion of patients who continued their index biologic treatment throughout the course of the study failed to achieve complete DLQI or PSI response, 
suggesting that there remains a need for more efficacious therapeutics for the treatment of all symptoms of psoriasis. Since enrollment into this study was completed in 2015, it did not include newer biologics such as brodalumab, ixekizumab, guselkumab, tildrakizumab and risankizumab. Several of these newer biologics have higher rates of efficacy compared with the older biologics, such as etanercept and ustekinumab, with patients more likely to achieve complete skin clearance [19-27]. Thus, realworld rates of complete skin clearance and, therefore, perhaps these PROs, may have improved since completion of this study.

A limitation of this study may be that the rates of patients achieving PSI 0 and DLQI $0 / 1$ were analyzed as observed, which may have overestimated the response rates, as patients that had discontinued the study were not included in the analysis. The rates of patients achieving PSI 0/responder status and DLQI 0 or $0 / 1$ were also higher at 12 months than at 6 months, which may have been due to fewer patients being observed at 12 months than at 6 months. Due to their design, in randomized controlled trials (RCTs), a non-responder imputation method is most often possible, which is a more conservative approach than that of observed analyses. Thus, the PSI and DLQI rates from this real-world study cannot be directly compared to those from RCTs due to differences in statistical analysis methodologies.

The correlation between PASI and both PSI and DLQI was not complete. Failure to achieve a complete association between all clinical measures and PROs may, to some degree, reflect that physician-reported measures may not sufficiently assess the impact of therapeutics on patient HRQoL [11]. The failure of patients in this study to achieve PSI 0 , or DLQI 0 or $0 / 1$, even with complete skin clearance (PASI 100 or absolute PASI 0), suggests that physician-reported skin clearance may not always mean that all aspects of the disease, such as HRQoL and subjective measures of symptoms, have been fully resolved. These additional elements captured by the PROs represent important insights in the evaluation of patients.

\section{CONCLUSIONS}

In this large, prospective, real-world study, only one in four patients experienced no symptoms of their psoriasis (PSI 0) while approximately one-half of the patients had no impact on their HRQoL (DLQI 0/1). Greater degrees of skin clearance were associated with more substantial improvements in HRQoL and with fewer psoriasis symptoms. Of note, complete skin clearance was associated with much higher rates of PSI/DLQI scores of 0 , even compared with almost complete skin clearance. There was not a complete correlation between patient- and physician-reported outcome measures, emphasizing the importance of considering both PROs and physician-reported outcomes when assessing treatment outcomes.

\section{ACKNOWLEDGEMENTS}

Funding. The PSO-BIO-REAL study was sponsored by Amgen and AstraZeneca. This manuscript and the journal's rapid service fee was sponsored by LEO Pharma.

Authorship. All named authors meet the International Committee of Medical Journal Editors (ICMJE) criteria for authorship for this article, take responsibility for the integrity of the work as a whole, and have given their approval for this version to be published.

Medical Writing and Editorial Assistance. Editorial support in the preparation of this article was provided by Robyn Foster, PhD from Adelphi Communications Ltd, Bollington, UK, funded by LEO Pharma.

Disclosure. Jean-Philippe Lacour has been a consultant for, has received grants from and/or has served as a speaker for AbbVie, Amgen, Boehringer Ingelheim, Celgene, Janssen, LEO Pharma, Eli Lilly, Novartis and Pfizer. Anthony Bewley has been a consultant for and received consultancy fees from AbbVie, Almiral, Galderma, Janssen, Novartis and UCB Pharma. Edward Hammond is an employee of 
AstraZeneca. Jes B. Hansen and Anne Sohrt are employees of LEO Pharma. Carle Paul has been a consultant for and has received grants from Almiral, Amgen, AbbVie, Boehringer Ingelheim, Celgene, Eli Lilly, Novartis, Janssen, Sandoz, Pfizer, LEO Pharma and UCB Pharma. Julien Seneschal has been a consultant for AbbVie, Eli Lilly, Janssen, Novartis and Pfizer. Clara De Simone has been a paid consultant and advisory board member for AbbVie, Almiral, Eli Lilly, Janssen, LEO Pharma, MSD, Novartis, Pfizer, Sanofi and UCB Pharma. Giovanni Pellacanihas been a consultant and received grants from LEO Pharma. Laura Horne, Kristian Reich and Matthias Augustin have nothing to disclose.

Compliance with Ethics Guidelines. All subjects provided informed consent to participate in the study. The study received IRB approval and was performed in accordance with the Helsinki Declaration of 1964 and its later amendments.

Data Availability. The datasets generated during and/or analyzed during the current study are available from the corresponding author on reasonable request.

Open Access. This article is licensed under a Creative Commons Attribution-NonCommercial 4.0 International License, which permits any non-commercial use, sharing, adaptation, distribution and reproduction in any medium or format, as long as you give appropriate credit to the original author(s) and the source, provide a link to the Creative Commons licence, and indicate if changes were made. The images or other third party material in this article are included in the article's Creative Commons licence, unless indicated otherwise in a credit line to the material. If material is not included in the article's Creative Commons licence and your intended use is not permitted by statutory regulation or exceeds the permitted use, you will need to obtain permission directly from the copyright holder. To view a copy of this licence, visit http://creativecommons.org/licenses/by$\mathrm{nc} / 4.0 /$.

\section{REFERENCES}

1. Armstrong AW, Schupp C, Wu J, et al. Quality of life and work productivity impairment among psoriasis patients: findings from the National Psoriasis Foundation survey data 2003-2011. PLoS ONE. 2012;7:e52935.

2. Menter A, Gottlieb A, Feldman SR, et al. Guidelines of care for the management of psoriasis and psoriatic arthritis: section 1 . Overview of psoriasis and guidelines of care for the treatment of psoriasis with biologics. J Am Acad Dermatol. 2008;58:826-50.

3. Gowda S, Goldblum OM, McCall WV, et al. Factors affecting sleep quality in patients with psoriasis. J Am Acad Dermatol. 2010;63:114-23.

4. Rapp SR, Feldman SR, Exum ML, et al. Psoriasis causes as much disability as other major medical diseases. J Am Acad Dermatol. 1999;41:401-7.

5. Strober B, Papp KA, Lebwohl M, et al. Clinical meaningfulness of complete skin clearance in psoriasis. J Am Acad Dermatol. 2016;75(77-82):e77.

6. Manalo IF, Gilbert KE, Wu JJ. Time to raise the bar to psoriasis area severity index 90 and 100. J Drugs Dermatol. 2015;14:1086-8.

7. Viswanathan HN, Chau D, Milmont CE, et al. Total skin clearance results in improvements in healthrelated quality of life and reduced symptom severity among patients with moderate to severe psoriasis. J Dermatolog Treat. 2015;26:235-9.

8. Revicki DA, Willian MK, Menter A, et al. Relationship between clinical response to therapy and health-related quality of life outcomes in patients with moderate to severe plaque psoriasis. Dermatology. 2008;216:260-70.

9. Feldman SR, Bushnell DM, Klekotka PA, et al. Differences in psoriasis signs and symptom severity between patients with clear and almost clear skin in clinical practice. J Dermatolog Treat. 2016;27: 224-7.

10. Blonde L, Khunti K, Harris SB, et al. Interpretation and impact of real-world clinical data for the practicing clinician. Adv Ther. 2018;35:1763-74.

11. Feldman SR, Krueger GG. Psoriasis assessment tools in clinical trials. Ann Rheum Dis. 2005;64(Suppl. 2): ii65-68 (discussion ii69-73).

12. Finlay AY, Khan GK. Dermatology Life Quality Index 1992. https://www.bad.org.uk/shared/getfile. ashx?id=1653\&itemtype=document. Accessed 10 Jan 2020. 
13. Bushnell DM, Martin ML, McCarrier K, et al. Validation of the Psoriasis Symptom Inventory (PSI), a patient-reported outcome measure to assess psoriasis symptom severity. J Dermatolog Treat. 2013;24: 356-60.

14. Martin ML, McCarrier KP, Chiou CF, et al. Early development and qualitative evidence of content validity for the Psoriasis Symptom Inventory (PSI), a patient-reported outcome measure of psoriasis symptom severity. J Dermatolog Treat. 2013;24: 255-60.

15. Gottlieb $\mathrm{AB}$, Gordon $\mathrm{K}, \mathrm{Hsu} \mathrm{S}$, et al. Improvement in itch and other psoriasis symptoms with brodalumab in phase 3 randomized controlled trials. J Eur Acad Dermatol Venereol. 2018;32:1305-13.

16. Seneschal J, Lacour JP, Bewley A, et al. A multinational, prospective, observational study to estimate complete skin clearance in patients with moderateto-severe plaque PSOriasis treated with BIOlogics in a REAL world setting (PSO-BIO-REAL). J Eur Acad Dermatol Venereol. 2020. https://doi.org/10.1111/ jdv. 16568 .

17. Nunnally JC. Psychometric theory. 2nd ed. New York: McGraw-Hill; 1978.

18. Cohen J. Statistical power analysis for the behavourial sciences. 2nd ed. New York: Lawrence Erlbaum Associates; 1988.

19. Takeshita J, Callis Duffin K, Shin DB, et al. Patientreported outcomes for psoriasis patients with clear versus almost clear skin in the clinical setting. J Am Acad Dermatol. 2014;71:633-41.

20. Blauvelt A, Reich K, Tsai TF, et al. Secukinumab is superior to ustekinumab in clearing skin of subjects with moderate-to-severe plaque psoriasis up to 1 year: results from the CLEAR study. J Am Acad Dermatol. 2017;76:60-9.
21. Lebwohl M, Strober B, Menter A, et al. Phase 3 studies comparing brodalumab with ustekinumab in psoriasis. N Engl J Med. 2015;373:318-28.

22. Papp KA, Reich K, Paul C, et al. A prospective phase III, randomized, double-blind, placebo-controlled study of brodalumab in patients with moderate-tosevere plaque psoriasis. Br J Dermatol. 2016;175: 273-86.

23. Reich K, Armstrong AW, Foley P, et al. Efficacy and safety of guselkumab, an anti-interleukin-23 monoclonal antibody, compared with adalimumab for the treatment of patients with moderate to severe psoriasis with randomized withdrawal and retreatment: results from the phase III, double-blind, placebo- and active comparator-controlled VOYAGE 2 trial. J Am Acad Dermatol. 2017;76:418-31.

24. Sawyer L, Fotheringham I, Wright E, et al. The comparative efficacy of brodalumab in patients with moderate-to-severe psoriasis: a systematic literature review and network meta-analysis. J Dermatolog Treat. 2018;29:557-68.

25. Blauvelt A, Papp KA, Lebwohl MG, et al. Rapid onset of action in patients with moderate-to-severe psoriasis treated with brodalumab: a pooled analysis of data from two phase 3 randomized clinical trials (AMAGINE-2 and AMAGINE-3). J Am Acad Dermatol. 2017;77:372-4.

26. Blauvelt A, Griffiths CEM, Lebwohl $M$, et al. Reaching complete or near-complete resolution of psoriasis: benefit and risk considerations. Br J Dermatol. 2017;177:587-90.

27. Gordon KB, Blauvelt A, Papp KA, et al. Phase 3 trials of ixekizumab in moderate-to-severe plaque psoriasis. N Engl J Med. 2016;375:345-56. 